\title{
EI Niño Impacts on Seasonal U.S. Atmospheric Circulation, Temperature, and Precipitation Anomalies: The OLR-Event Perspective*
}

\author{
ANDREW M. CHIODI \\ Joint Institute for the Study of the Ocean and Atmosphere, University of Washington, Seattle, Washington \\ DON E. HARRISON \\ NOAA/Pacific Marine Environmental Laboratory, Seattle, Washington
}

(Manuscript received 17 February 2012, in final form 30 May 2012)

\begin{abstract}
This study shows that, since 1979 when outgoing longwave radiation (OLR) observations became reliably available, most of the useful U.S. seasonal weather impact of El Niño events is associated with the few events identified by the behavior of outgoing longwave radiation (OLR) over the eastern equatorial Pacific ("OLREl Niño events"). These events produce composite seasonal regional weather anomalies that are $95 \%$ statistically significant and robust (associated with almost all events). Results also show that there are very few statistically significant seasonal weather anomalies, even at the $80 \%$ level, associated with the non-OLR-El Niño events. A major enhancement of statistical seasonal forecasting skill over the contiguous United States appears possible by incorporating these results. It is essential to respect that not all events commonly labeled as El Niño events lead to statistically useful U.S. seasonal forecast skill.
\end{abstract}

\section{Introduction}

The El Niño-Southern Oscillation (ENSO) is the strongest low-frequency coupled atmosphere-ocean phenomenon after the seasonal cycle and involves major disruptions of both the atmospheric and oceanic circulation, particularly in the tropical Pacific but also elsewhere. Substantial seasonal surface temperature and precipitation anomalies around the world, particularly in the cool seasons, have been associated with its warm (El Niño) and cool (La Niña) phases (e.g., Ropelewski and Halpert 1996; Kiladis and Diaz 2009; Larkin and Harrison 2005a,b). Where statistically strong enough, these linkages form a basis for predicting seasonally averaged ("seasonal") weather anomalies in the relevant regions and seasons.

\footnotetext{
* National Oceanic and Atmospheric Administration Contribution Number 2050 and Pacific Marine Environmental Laboratory Contribution Number 3281.

Corresponding author address: Andrew Chiodi, JISAO, University of Washington, 7600 Sand Point Way NE, Seattle, WA 98115.

E-mail: andy.chiodi@noaa.gov
}

Composites of global and U.S. seasonal temperature and precipitation anomalies over years identified as El Niño or La Niña have been used to identify the associations between seasonal weather anomalies and ENSO. But even in the most strongly affected regions and seasons, considerable differences in strength and spatial pattern exist between the seasonal weather anomalies seen in the commonly identified ENSO years. For example, in an examination of the effects of El Niño on U.S. seasonal weather anomalies, Harrison and Larkin (1998) found that upper-quintile temperature and precipitation extremes with the same sign as the composite El Niño average occurred in, at best, only about half of the El Niño years identified by them, and with much less frequency in most U.S. regions. Further, they found that upper-quintile anomalies of sign opposite to the composite anomaly were not uncommon in many regions. While these relationships have become an important foundation for forecasting seasonal weather anomalies (see also Wolter et al. 1999; Smith et al.1999), it is worth exploring whether improved statistical forecast skill can be obtained.

There has been discussion recently about whether the commonly used ENSO definitions, which are based on tropical Pacific surface marine variability [e.g. sea surface temperature (SST)-based Niño-3 and Niño-3.4 indices 
and the sea level pressure (SLP)-based Southern Oscillation index (SOI)] can be improved upon for the purposes of regional seasonal weather prediction over the contiguous United States (cf. Larkin and Harrison 2005a,b; Weng et al. 2009). Our work indicates that it can.

Our focus in this paper is on the connection between El Niño and seasonal North American and North Pacific atmospheric circulation anomalies. Current understanding posits that the chain of events that allows an El Niño event in the tropical Pacific to influence midlatitude seasonal weather conditions depends upon anomalous atmospheric heating across at least the tropical Pacific. The anomalous heating results from changes in the location and patterns of deep atmospheric convection, which are associated with but not entirely determined by anomalous SST. We find that going directly to outgoing longwave radiation, which provides a measure of anomalous atmospheric heating, is key.

Chiodi and Harrison (2010) have recently proposed an El Niño index based on outgoing longwave radiation (OLR) behavior in the eastern central tropical Pacific, where OLR is thought to provide a good proxy for deep atmospheric convection. OLR behavior in this region exhibits statistically different characteristics than seen in the commonly used ENSO indices (Chiodi and Harrison 2010); notably, it is more "eventlike," exhibiting some peaks that stand out clearly from the background variability seen at other times. To streamline its foreseen operational use, we have proposed a redefinition of the OLR index averaging region, as described further in the data and methods section. The redefinition enhances the eventlike quality of the index while preserving the original events identified over the study period. We describe here some statistical connections between the events identified by this OLR-El Niño index and midlatitude atmospheric circulation anomaly behavior that are novel.

To examine the relationship between the behavior of this OLR-El Niño index and atmospheric circulation anomalies in the North Pacific and over North America we perform composite analysis of atmospheric behavior in the years for which OLR observations are routinely available (period 1979-2008). Composites based on the OLR-El Niño events are described and compared with those based on other years that have El Niño status based on the current National Oceanographic and Atmospheric Administration (NOAA) historical definition, but are different from those distinguished by OLR behavior. We focus first on 500-mb geopotential height anomalies, which are known by meteorologists to be closely linked to U.S. seasonal weather anomalies. Since it is the seasonal weather anomalies that are ultimately the main socioeconomic concern, we also examine the behavior of U.S.

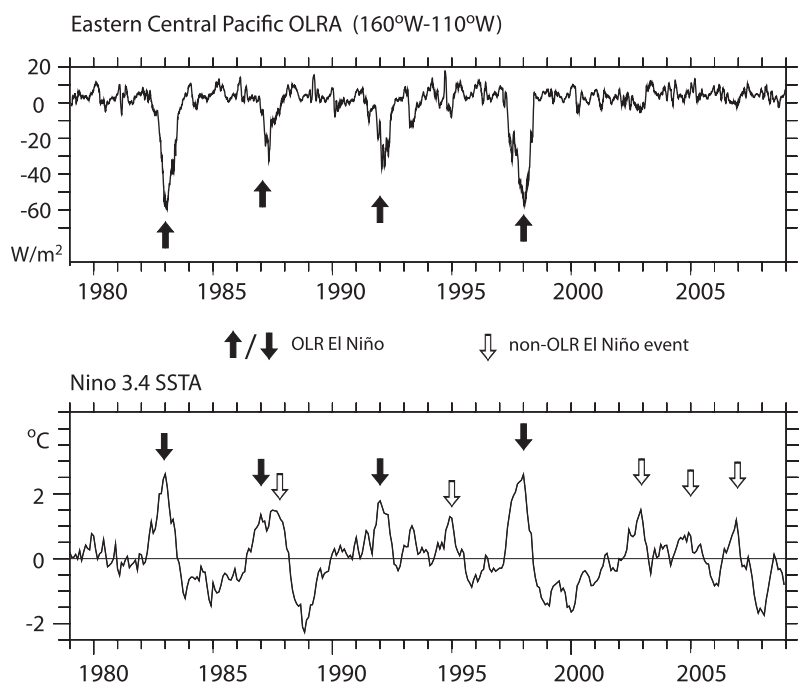

FIG. 1. (top) The OLR-El Niño index and (bottom) the Niño-3.4 SSTA-based index. Solid arrows mark OLR-El Niño events. Unfilled arrows mark the other years also commonly defined as El Niño years.

seasonal temperature and precipitation anomalies. We show that these results will be directly useful to U.S. seasonal statistical weather prediction efforts.

\section{Data and methods}

Interpolated daily-average OLR data (Liebmann and Smith 1996) was obtained from the NOAA/Office of Oceanic and Atmospheric Research (OAR)/Earth System Research Laboratory (ESRL) Physical Sciences Division (PSD), Boulder, Colorado, via their website (at http://www.esrl.noaa.gov/psd/). The record dates back to 1974, but includes a gap from March through December 1978. Our study period is January 1979 through December 2008. Anomalies were determined by removing the linearly interpolated climatological monthly average. A climatological base period of 19792008 is used throughout this paper.

The OLR-El Niño index shown herein (Fig. 1) is the monthly (30-day running average) OLR anomaly over the region bounded by $5^{\circ} \mathrm{S}-5^{\circ} \mathrm{N}, 160^{\circ}-110^{\circ} \mathrm{W}$. This is a subset of the region discussed originally by Chiodi and Harrison (2010), which used $170^{\circ} \mathrm{E}$ and $100^{\circ} \mathrm{W}$ as boundaries. The $170^{\circ} \mathrm{E}-160^{\circ} \mathrm{W}$ part of the original index has been omitted because examination has shown that it exhibits comparable peak anomalies in a variety of conditions that include, but are not limited to, the four large events seen in Fig. 1. The same four events are distinguished by the index regardless of which averaging region is used; they just stand out from background variability more clearly using the modified $\left(160^{\circ}-110^{\circ} \mathrm{W}\right)$ region. The index based on both the original Chiodi and Harrison (2010) and 
redefined regions are shown in appendix A for reference. The redefinition does not affect the results of the compositing analysis described below; we see it being useful from an operational perspective.

Monthly average 500-mb-level geopotential height (z500) fields were obtained from the National Centers for Environmental Prediction (NCEP) reanalysis data (Kalnay et al. 1996), and are provided by NOAA/OAR/ ESRL PSD from their website (http://www.esrl.noaa. gov/psd/data/gridded/data.ncep.reanalysis.html).

Monthly average temperature and precipitation data for each of the 344 defined U.S. climate divisions were obtained from NOAA's National Climatic Data Center (NCDC 1994), from their website (http://www.ncdc.noaa. gov/temp-and-precip/us-climate-divisions.php).

The statistical significances of the composite average z500 and temperature anomalies were determined at each grid point using Student's $t$ method for testing against the null hypothesis that the actual composite anomaly is zero. For precipitation, which is not normally (Gaussian) distributed, we use a Monte Carlo/bootstrap method (Efron and Tibshirani 1991), based on random sampling of the precipitation anomalies seen in the study period, to estimate the anomaly statistical significance.

Substantial seasonal weather anomalies occur each year regardless of ENSO state, and at least a few of the 344 U.S. climate regional divisions are likely to (misleadingly) show statistically significant composite anomalies regardless of the particular years chosen. It is therefore useful in studies like this, which considers the variability of the many different climate regions that span the contiguous United States, to determine whether general characteristics of the anomaly pattern (e.g., the total number of individual climate divisions with statistically significant anomalies) are statistically significant in an overall sense. To do this here, we estimate the overall "field significance" (Livezey and Chen 1983) for each composite by tabulating the percentage of climate divisions that yield a given attribute (e.g., statistical significance or robustness, as described below) and comparing this percentage to the Monte Carlo/bootstrap probability $(N=10000)$ of obtaining that value by random selection (with replacement). General attributes that are determined unlikely to occur by chance are then said to be statistically ("field") significant.

\section{The OLR perspective on El Niño}

The behavior of OLR in the eastern central equatorial Pacific clearly distinguishes four satellite-era years (1982/83, 1986/87, 1991/92, and 1997/98) from the background variability seen at other times (Fig. 1a).

The years distinguished by OLR behavior have commonly been identified as El Niño years in the scientific
TABLE 1. Dates at which the monthly (30-day-running mean) OLR-El Niño index first crosses the $-20 \mathrm{~W} \mathrm{~m}^{-2}$ value during the OLR-El Niño events.

\begin{tabular}{ccccc}
\hline \hline $\begin{array}{c}\text { OLR-El Niño } \\
\text { year }\end{array}$ & $1982-83$ & $1991-92$ & $1986-87$ & $1997-98$ \\
\hline Date & October & November & March & May \\
& 1982 & $1991 *$ & 1987 & 1997 \\
\hline
\end{tabular}

* The index magnitude weakens in December 1991 before crossing the $-20 \mathrm{~W} \mathrm{~m}^{-2}$ value again and strengthening well beyond it in January 1992.

literature, but not without some debate. Although the strong events of 1982/83 and 1997/98 are virtually unanimous in this respect, 1986/87 is sometimes omitted in favor of the stronger sea surface temperature anomaly (SSTA) amplitudes seen in 1987/88, and both 1986/87 and 1991/92 have been classified differently than 1982/83 and $1997 / 98$ by some recent studies that focus on differences in tropical Pacific SSTA-warming patterns (see Weng et al. 2009; Kug et al. 2009). Although many similarities are evident between tropical Pacific surface marine and OLR variability (cf. Figs. 1a and 1b), the OLR perspective does not easily emerge from consideration of surface marine variability alone. Notably, broadscale deep atmospheric convection conditions do not reach the eastern equatorial Pacific in all of the years with warm SSTAs in the eastern central tropical Pacific (e.g., Niño-3 or Niño-3.4 averaging regions). We will refer to the four events distinguished by OLR behavior as the OLR-El Niño events. In addition to these four events, five others in the 1979-2008 period are also defined as El Niño events by the current NOAA historical El Niño definition but not distinct based on OLR behavior. We refer to these five events as the non-OLR-El Niño events.

For reference purposes we list in Table 1, for each of the four OLR-El Niño events, the months in which the monthly OLR-El Niño index first crossed $-20 \mathrm{~W} \mathrm{~m}^{-2}$, a value that is not seen in any of the other years in record (no other peak anomaly crosses $-15 \mathrm{~W} \mathrm{~m}^{-2}$ ). The OLR-El Niño index crosses this threshold by the beginning of winter in each of the four events except 1986/87. Trial shows that small decreases in this threshold (e.g., using the $-1.5 \sigma$ value of $17.5 \mathrm{~W} \mathrm{~m}^{-2}$ ) can be made without changing the dates listed in Table 1, whereas increases eventually highlight the larger events of 1982/83 and 1997/98.

Composite analysis shows that the wintertime (December through February) average OLR anomaly conditions during the four OLR-El Niño events exhibit a broad and statistically significant negative anomaly that spans the central and eastern equatorial Pacific. A statistically significant and positive anomaly is also seen in the far western Pacific in the OLR-El Niño event composite 
OLR-El Niño events

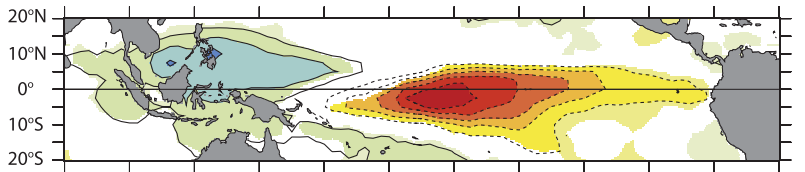

non-OLR events

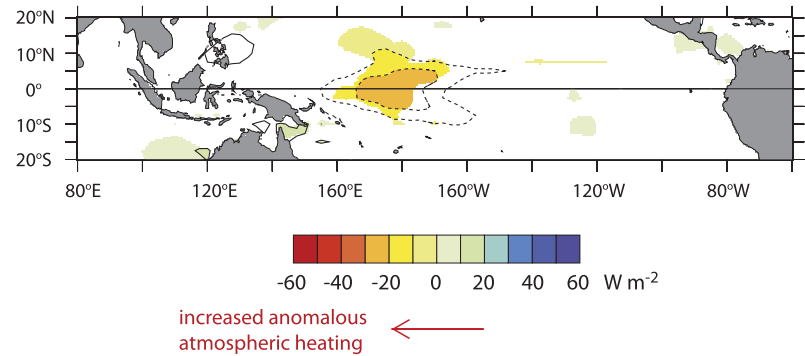

FIG. 2. Wintertime OLR anomaly composites for (top) the four OLR-El Niño events and (bottom) five non-OLR-El Niño events, period 1979-2008. The contour interval is $10 \mathrm{~W} \mathrm{~m}^{-2}$ (zero omitted), with shading where the composite anomalies are statistically significant at the 95\% level based on bootstrap/Monte Carlo methods.

(Fig. 2a). Thus, although the OLR-El Niño events are usefully distinguished by the unusual occurrence, as seen at monthly time scales, of deep atmospheric convection conditions in eastern central tropical Pacific (i.e., $160^{\circ}-$ $110^{\circ} \mathrm{W}$ ), the seasonal-scale atmospheric heating anomalies that occur during these events are not limited to the zonal bounds of the OLR index averaging region. On the other hand, statistically significant (negative) OLR anomaly at this time is mostly only seen near the date line in the nonOLR-El Niño case (Fig. 2b).

\section{Composite atmospheric circulation anomalies}

To examine the midlatitude atmospheric circulation anomalies that occur during these events we composite seasonally averaged 500-mb geopotential height anomalies $\left(\mathrm{z} 500^{\prime}\right)$ using two different lists of years. The first includes the four OLR-El Niño events (1982/83, 1986/ $87,1991 / 92,1997 / 98)$ and the second includes the five non-OLR-El Niño events (1987/88, 1994/95, 2002/03, 2004/05, 2006/07). We focus first on wintertime [DecemberFebruary (DJF)] averages.

The anomaly patterns in the OLR and non-OLR z500' composites are quite different. In the DJF OLRevent case, a coherent negative anomaly is seen in the North Pacific along with a positive anomaly over much of central Canada and the northern United States such that the contour lines between these two extremes (signifying the direction of the anomalous $500-\mathrm{mb}$ geostrophic flow) roughly align with the western North American coastline (Fig. 3a). Also, a negative anomaly is seen over much of the southern United States and Mexico. Much of this anomaly pattern, including regions over North America, is statistically significant in a local sense (red shading). Based on the fraction of the area shown with locally statistically significant anomaly, the OLR-event z500' composite is field significant at the $98 \%$ confidence level. The pattern seen in this case is very similar to others previously attributed to ENSO forcing (e.g., Hoerling and Kumar 2002).

A different sort of behavior is seen in the non-OLRevent composite (Fig. 3b). In this case, a positive anomaly occurs over northwestern Canada, but it is relatively weak, not locally statistically significant, and displaced far to the northwest of the positive anomaly that is located over the northern United States and central Canada in the OLR-event case. The non-OLR-event z500' composite also lacks statistically significant anomalies (gray shading) over the North Pacific and the contiguous United States

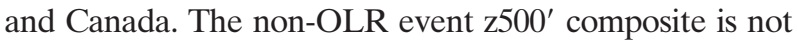
field significant.

It is useful to also consider composites based on all nine of the events comprising the OLR- and non-OLRevent year lists. A similar anomaly pattern is seen in both the OLR- and nine-event DJF z500'composites (cf. Figs. 3a and 3c). Both cases yield field significant anomaly patterns ( $p=0.98$ and 0.95 , respectively). However, the amplitude of the OLR-event composite anomaly (peak negative anomalies about $-80 \mathrm{~m}$ ) is roughly double that of the nine-event composite anomaly (peak negative anomalies about $-40 \mathrm{~m}$ ): the non-OLR years do not contribute much to the pattern seen in the 9-yr composite.

We have also examined the extent to which the z500 anomalies seen in each of the four individual OLR events resemble the $\mathrm{z} 500$ ' composite. Although some pattern and intensity details vary from year to year, visual inspection (individual DJF z500' averages are shown in appendix B, Fig. B1) shows that similar features appear over the North Pacific (negative anomaly), across much of the southern United States and Mexico (negative anomaly), and over much of the Great Lakes region and central Canada (positive anomaly) in each of the four OLR-event years. And although the behavior seen over the North Atlantic and surrounding regions differs in each of these four years, the overall robustness of the OLR composite is good; based the extent of the area with the same-sign anomaly in each of these four years (shown by shading in Fig. B1), our Monte Carlo methods estimate that the OLR composite is field significant at the $99 \%$ confidence level.

In contrast, each of the DJF z500 anomalies seen in the five non-OLR events (shown in Fig. B2) have a considerably different character, suggesting that the effects of tropical Pacific forcing on the mean regional atmospheric circulation during these events are secondary to other sources of midlatitude atmospheric variability. Based on the extent of the area with the 


\section{DJF}

a) Four OLR Events

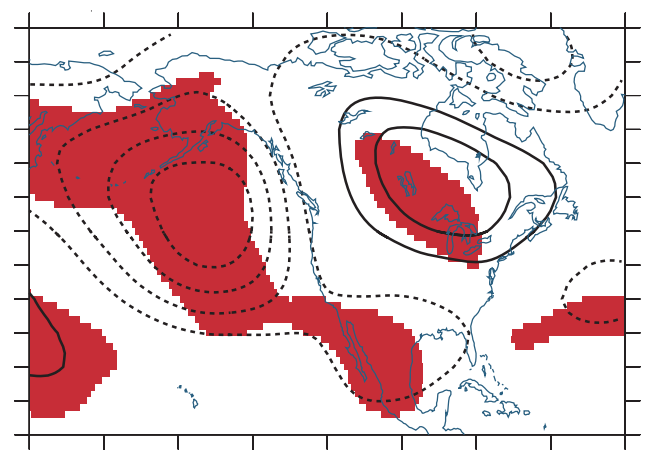

b) Five non-OLR Events

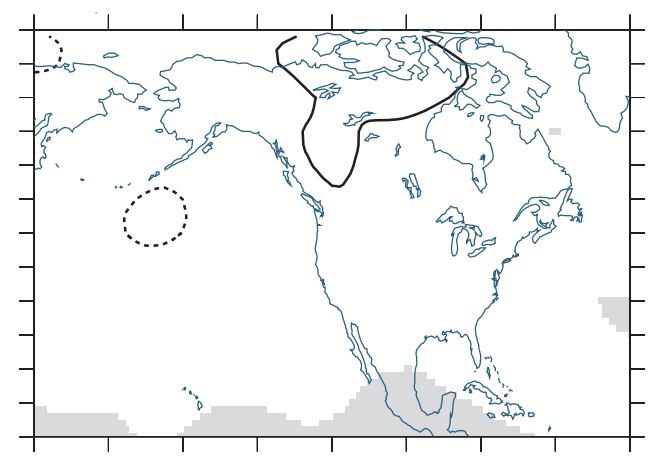

c) Nine Event Composite Average

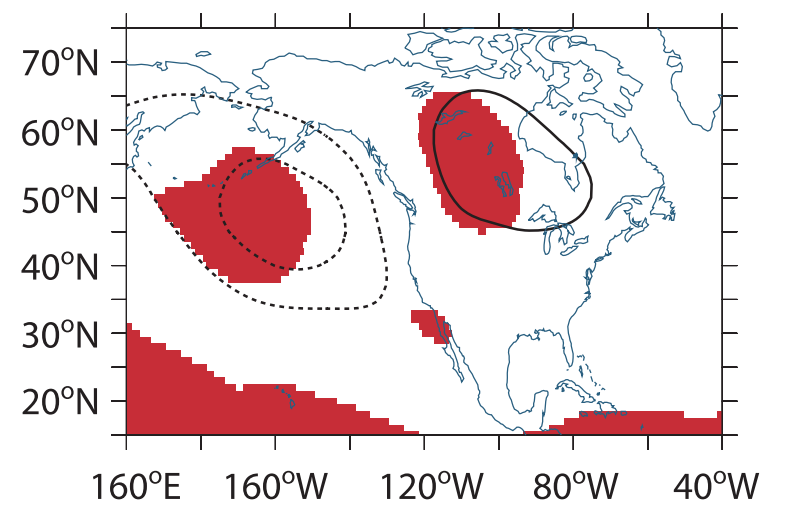

FIG. 3. Wintertime composite geopotential height anomalies.
Contours every $20 \mathrm{~m}$

Shading at $95 \%$ local significance:

not field significant

95\% field significance same sign anomaly in each of these five years, the nonOLR-event composite does not approach field significance $(<50 \%$ confidence level, even taking into account that five rather than four years are considered in this case).

We have also examined OLR and non-OLR event z500' composites for the overlapping three-month averages from September-November (SON) through March-May (MAM), but found that only the OLRevent composites based on November-January (NDJ), DJF, and January-March (JFM) averages yield field significant $\mathrm{z} 500^{\prime}$ anomaly patterns $(>90 \%$ confidence level). Unsurprisingly, the pattern is seen in each of these three overlapping OLR-event cases is similar (appendix C, Fig. C1). A weaker, but recognizable pattern, is also seen in the subsequent February-April (FMA) average. None of the non-OLR-event z500' composites yield field significant anomalies (not shown). We turn attention now to DJF-average temperature and precipitation anomaly composites over the contiguous United States.

\section{Temperature anomalies}

The composite DJF temperature anomaly from the four OLR-El Niño years is shown in Fig. 4a, with shading provided in each of the 344 U.S. climate divisions that reach statistical significance $(p>0.95)$ in a local sense. Coherent and statistically significant warm anomalies, with amplitude $>3^{\circ}$, are seen over much of the north-central United States, along with anomalously cool temperatures in several southwestern states. The OLR-El Niño DJF temperature composite is field significant $(98 \%)$ based on the number of climate divisions (126) that yield statistically significant anomalies.

The non-OLR-event composite (Fig. 4b) has few regions with statistically significant temperature anomalies, and is not field significant.

The nine-event composite (Fig. 4c) has statistically significant warm anomalies in many of the same northcentral regions seen in the OLR-event composite, although smaller amplitudes are generally seen in these 


\section{DJF Temperature}

a) Four OLR Events

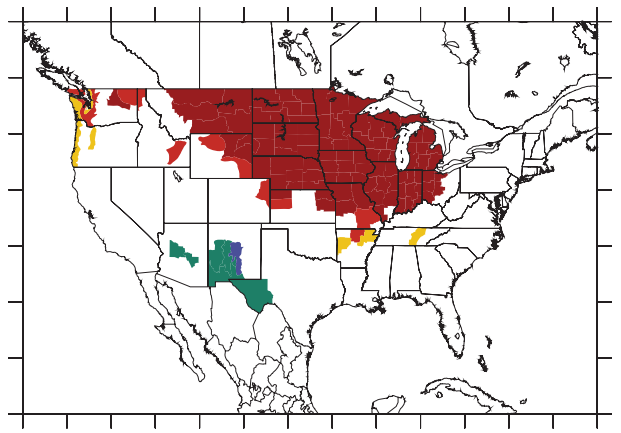

c) Nine Event Composite Average

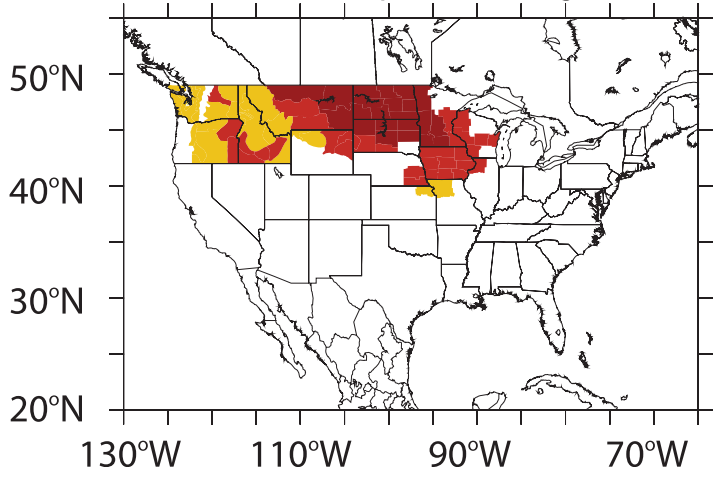

b) Five non-OLR Events
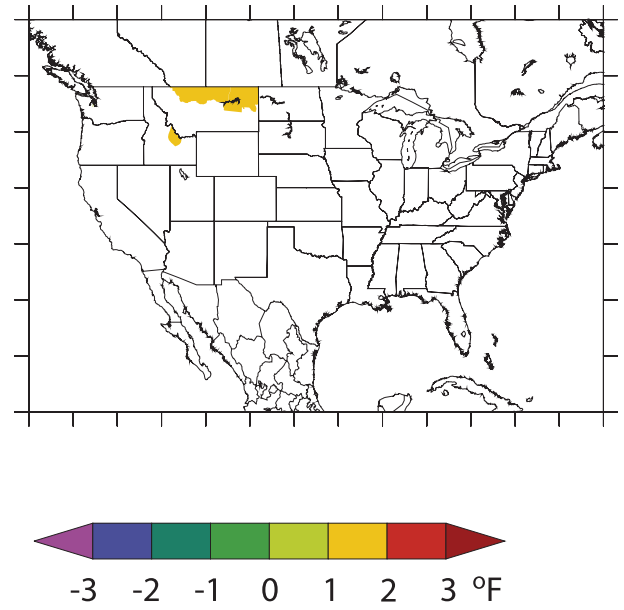

Shading at $95 \%$ significance

FIG. 4. Wintertime composite temperature anomalies.

regions in the 9-yr composite. The southwestern United States does not have statistically significant anomalies in the 9-yr composite, although the additional regions of the Pacific Northwest that reach statistical significance in this case, but not in the OLR-event case, allow the nine-event composite to reach field significance $(95 \%$ level).

We have examined the individual DJF-average temperature anomalies from each of the four OLR-El Niño events (shown in appendix B, Fig. B3), and found that the main features of the composite anomaly pattern are consistent in each (as opposed to perhaps being the result of disproportionately-large anomalies in just one or two of the years). Substantial $\left(>3^{\circ}\right)$ warm anomalies are seen over a large and coherent block of the north to north-central United States in each of these four years. And, albeit with some variation in their extent and position, cool anomalies are also seen in the Southwest in each of these seasonal anomalies, confirming good robustness for this anomaly feature as well. The anomalies seen in these four years in other regions, such as the midAtlantic and New England states, however, have different characteristics in each year.
Unlike the OLR-event case, the DJF-averaged temperature anomaly patterns seen during the five nonOLR-event years (Fig. B4) are substantially different from one another. It may be notable, however, that 1994/95 and 2002/03, the two non-OLR-event years with height anomalies that are negative in the North Pacific and positive across the northern/northwest United States show coherent warming over much of the western United States (cf. Figs. B2 and B4).

\section{Precipitation anomalies}

The composite average DJF precipitation anomaly over the four OLR-event years is shown in Fig. 5a. In this composite, substantial $\left(>1\right.$ in. month $\left.{ }^{-1}\right)$ and statistically significant wet anomalies are seen over many of the regions bordering the Gulf of Mexico, the midAtlantic coast, and in the southern United States. Some indications of dry conditions are also evident in Montana and the Ohio Valley, but over far fewer regions than experience statistically significant wet conditions. This composite anomaly is moderately field significant (93\%). 


\section{DJF Precipitation}

a) Four OLR Events

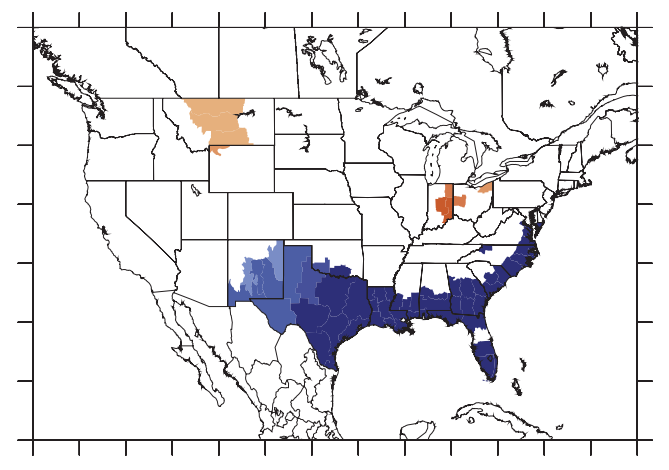

b) Five non-OLR Events

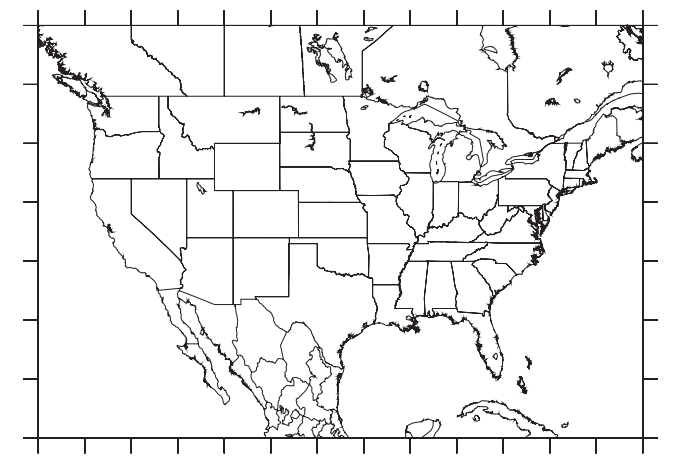

c) Nine Event Composite Average
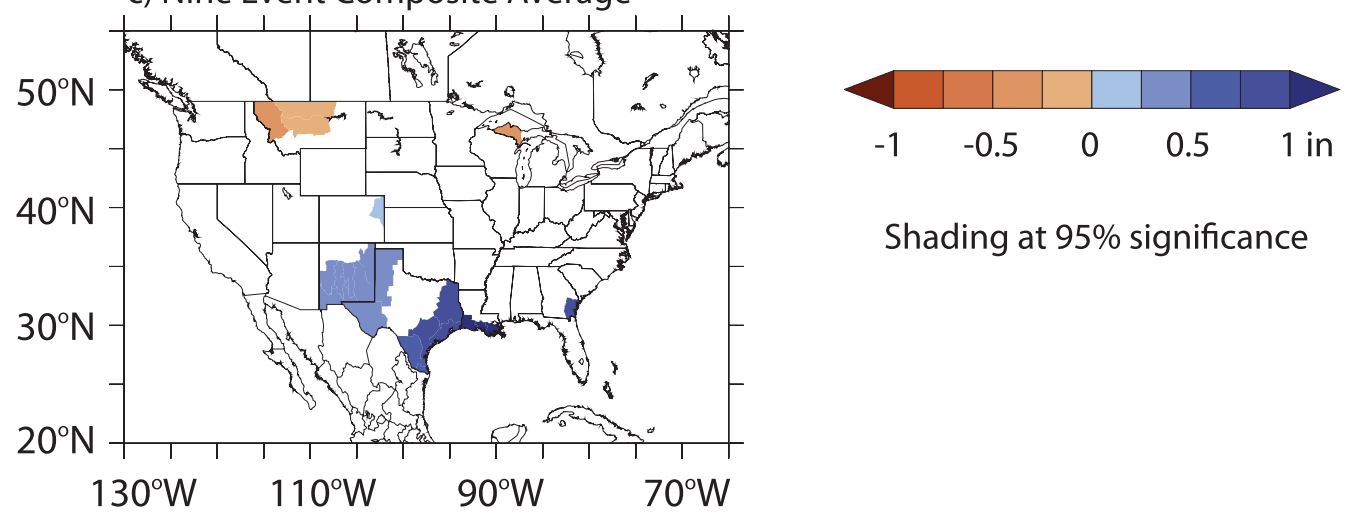

Shading at $95 \%$ significance

FIG. 5. Wintertime composite precipitation anomalies.

The non-OLR-event DJF precipitation composite (Fig. 5b) has very few regions with statistically significant $(>95 \%)$ temperature anomalies and is not field significant.

The nine-event precipitation composite bears some resemblance to the OLR-event composite in that some of the same regions are significantly wetter/dryer than usual, but unlike the OLR-event case, the nine-event composite is not field significant $(<80 \%)$.

Comparison of the DJF-average precipitation anomalies during the four OLR-event years shows that many of the same Gulf Coast, mid-Atlantic, and southern U.S. regions experienced unusually wet conditions in each of these four years, although the intensity of these conditions varied considerably from year to year (appendix B, Fig. B5). Other U.S. regions experienced mainly a mix of wet and dry conditions in these years.

We have examined the DJF-average precipitation anomalies during the five non-OLR event years (shown in appendix B, Fig. B6), but find it difficult to identify characteristics that are substantial and common to all five, or even just four out of these five years.

\section{Discussion and conclusions}

The seasonally averaged $z 500$ ', temperature, and precipitation anomalies seen during the recent El Niño events that are distinguished by OLR behavior in the easterncentral equatorial Pacific reveal highly statistically significant wintertime weather anomaly patterns with good event-to-event consistency over much of the contiguous United States. The seasonal temperature anomaly patterns seen during these years are characterized mainly by the now-familiar warmer than usual wintertime temperatures across much of the northern, especially north-central, United States, and the precipitation patterns by significantly wetter than usual wintertime conditions in many southeastern U.S. states. The fall and spring seasonal weather anomaly composites do not have nearly the levels of robustness and statistical significance seen in the wintertime composites.

Many features of the OLR-El Niño wintertime anomalies are recognizable in previous, and in some cases now long-standing, studies of midlatitude atmospheric 
variability (see Wallace and Gutzler 1981 for a seminal examination of regional atmospheric circulation patterns). The novel result here is that the wintertime anomaly patterns seen in the OLR-El Niño years are much more highly robust and statistically significant than the other years identified as El Niño by the NOAA definition. In particular, the non-OLR-El Niño years do not often exhibit the seasonal U.S. weather anomalies of the OLR-El Niño events.

Compared to the OLR-El Niño events, the nonOLR-El Niño years have wintertime tropical Pacific OLR anomalies that are much weaker and of limited extent. We imagine that the relative lack of U.S. seasonal weather anomalies during the non-OLR-El Niño years results from this much reduced anomalous atmospheric heating. However, attribution studies with dynamical models capable of reproducing the observed links between tropical OLR conditions and the extratropical atmospheric variability will be needed to gain a better understanding of the dynamically key OLR features.

We have attempted but so far been unable to distinguish OLR and non-OLR events based on the observed spatial distribution of tropical Pacific SSTA alone. While it is perhaps not surprising that the two El Niño events with the largest SSTAs $(1982 / 83,1997 / 98)$ are in the OLR event group, and the smallest (2004/05) in the non-OLR event group, it is difficult to identify other SSTA characteristics that are unique to either. Some recent studies have called attention to event-to-event differences in the locations [e.g. central versus eastern tropical Pacific] of the maximum El Niño SSTAs (e.g., Larkin and Harrison 2005a,b; Kug et al. 2009; Weng et al. 2009). We, however, find no simple relationship between this aspect of SSTA and OLR behavior. For example, both OLR-events $(1986 / 87,1991 / 92)$ as well as non-OLR events $(1994 / 95$, 2002/03) have DJF SSTAs with similar amplitude maxima located in the central rather than far eastern Pacific. Likewise, DJF SSTA maxima in the far eastern Pacific (seen in 1982/83, 1997/98, and 2006/07, albeit with different amplitudes) are not unique to either group.

It can now be seen that forecasts based on previous statistical linkages that include the OLR-El Niño events along with the non-OLR-El Niño events will be dominated by the impacts seen during the OLR-El Niño events and not be representative of the others. To the extent that this behavior, evident in the 30 -yr period for which highquality OLR information is reliably available, remains unchanged in the coming decades, distinguishing among OLR and non-OLR-El Niño events offers a means for improving forecasts of U.S. wintertime weather conditions.

It is notable that the OLR-El Niño index has tended to distinguish the OLR-El Niño years from others before the arrival of the wintertime impacts (three out of four cases, 1986/87 being the exception). It is difficult to know if this aspect of the OLR-El Niño event behavior will typify future events, but to the extent it continues the OLR-El Niño index and OLR-El Niño seasonal weather anomaly composites described here will provide a useful basis for seasonal forecasting in the affected U.S. regions. The processes controlling the underlying tropical Pacific OLR behavior, and whether OLR-El Niño events can be predicted in advance of their operational identification remains uncertain, but may provide fruitful ground for future study.

Acknowledgments. This publication is (partially) funded by the Joint Institute for the Study of the Atmosphere and Ocean (JISAO) under NOAA Cooperative Agreement NA10OAR4320148.

\section{APPENDIX A}

\section{Comparison of the Redefined and Chiodi and Harrison (2010) OLR EI Niño Indices}

The OLR-based El Niño index discussed above and by Chiodi and Harrison (2010) is shown here for reference purposes. Note that the same four pairs of years $(1982 / 83,1986 / 87,1991 / 92,1997 / 98)$ are distinguished by large events in each case, but more so in the redefined index (upper panel of Fig. A1), because compared to the Chiodi and Harrison (2010) version, it omits the near date line $\left(170^{\circ} \mathrm{E}-160^{\circ} \mathrm{W}\right)$ region, which shows comparable strong anomalies in a number of years that include, but are not limited to, those distinguished by the four large events.

\section{APPENDIX B}

\section{The DJF Geopotential Height, Temperature, and Precipitation Anomalies Seen in Individual Years}

The 500-mb geopotential height (Fig. B1 and B2), temperature (Fig. B3 and Fig. B4), and precipitation anomalies (Fig. B5 and Fig. B6) averaged over the individual DJF periods that comprise the OLR-El Niño event and non-OLR-El Niño event lists are shown herein.

\section{APPENDIX C}

\section{Composite Geopotential Height Anomaly in Overlapping Seasons}

The OLR-El Niño z500' composites for each of the overlapping 3-month periods from boreal fall (SON) to spring (MAM) are shown herein. Unlike the OLR-event case, the non-OLR-El Niño composites (not shown) do not yield field significant anomalies in any of the 3-month periods considered (Fig. C1). 


\section{OLRA}
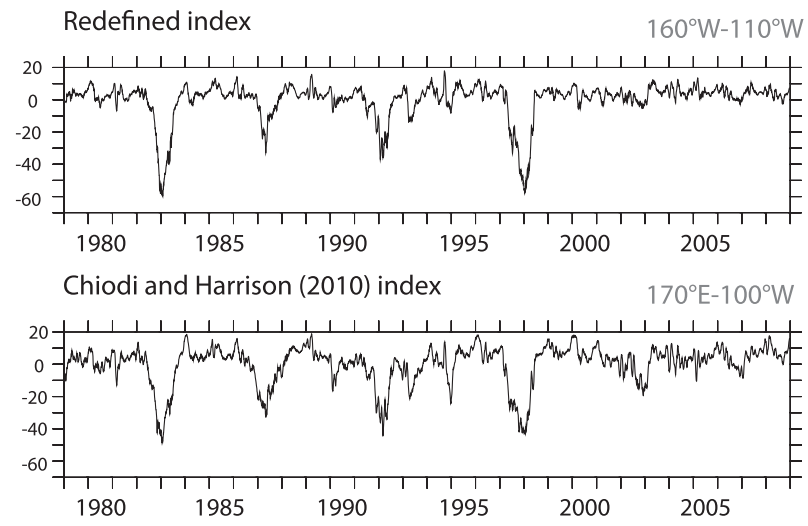

FIG. A1. OLR anomaly averaged over the box bounded by $5^{\circ} \mathrm{S}-$ $5^{\circ} \mathrm{N}$ and (top) $160^{\circ}-110^{\circ} \mathrm{W}$; (bottom) $170^{\circ} \mathrm{E}-110^{\circ} \mathrm{W}$. The curve in the top panel is repeated from Fig. 1 for comparison.

\section{DJF}
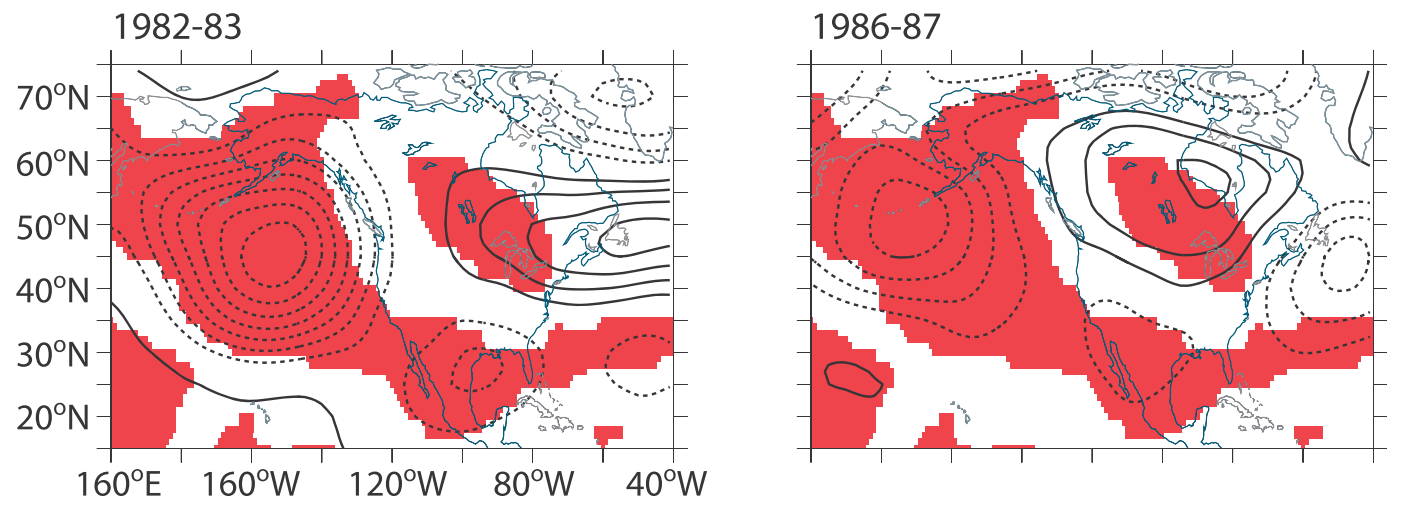

$1991-92$
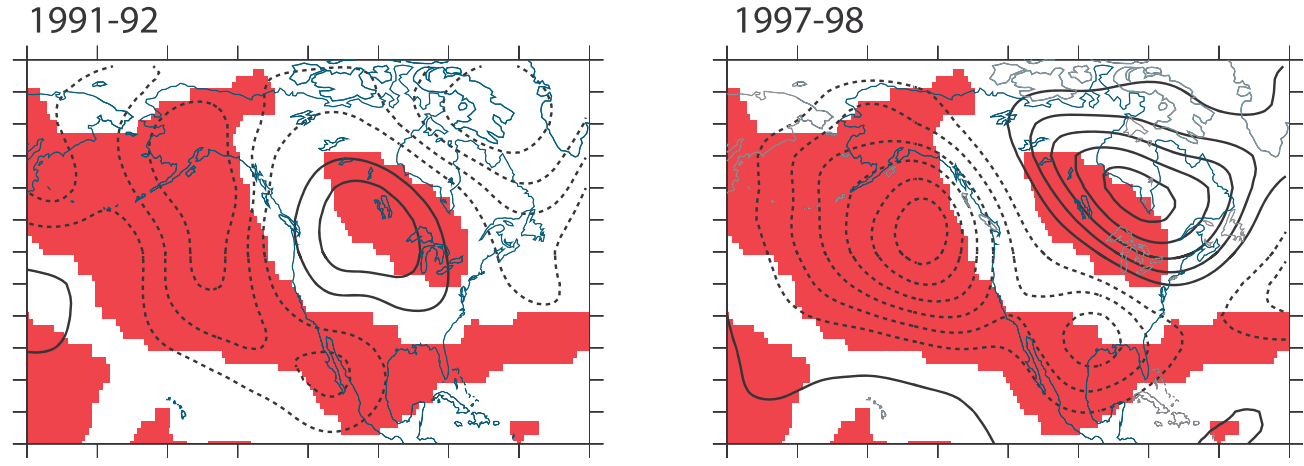

Same-sign anomaly in all four panels (coverage is field significant)

FIG. B1. Wintertime geopotential height anomalies during the four OLR-El Niño years. 


\section{DJF}
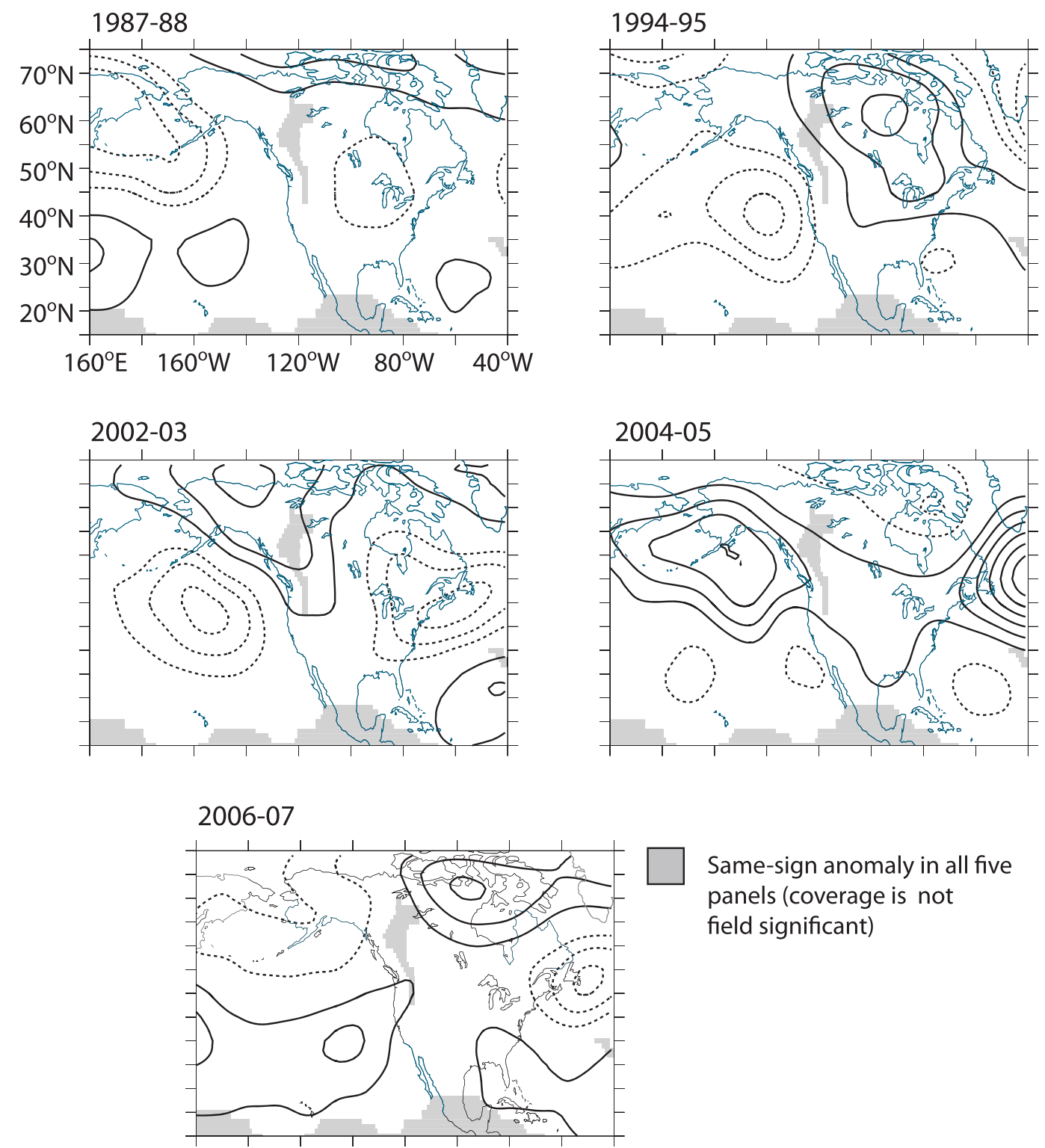

Same-sign anomaly in all five panels (coverage is not field significant)

FIG. B2. Wintertime composite geopotential height anomalies during the five non-OLR-El Niño years. 


\section{DJF Temperature Anomalies}

1982-83

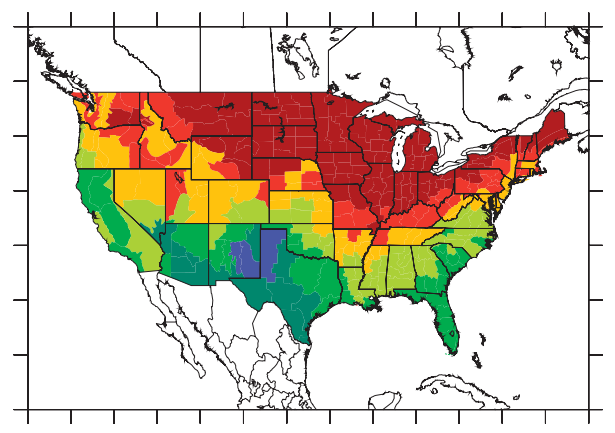

1991-92

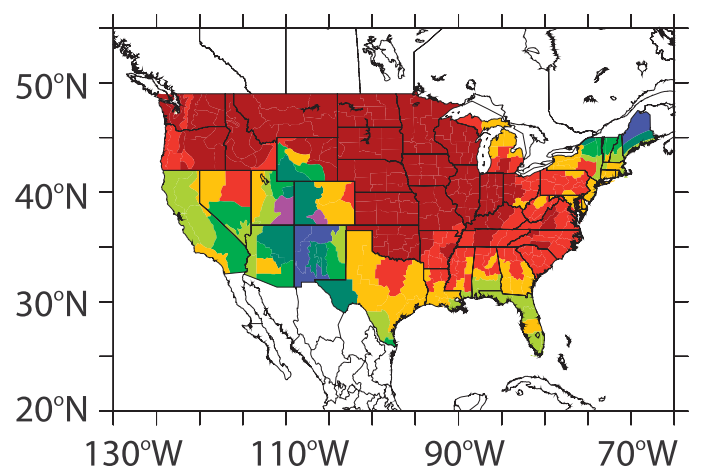

1986-87

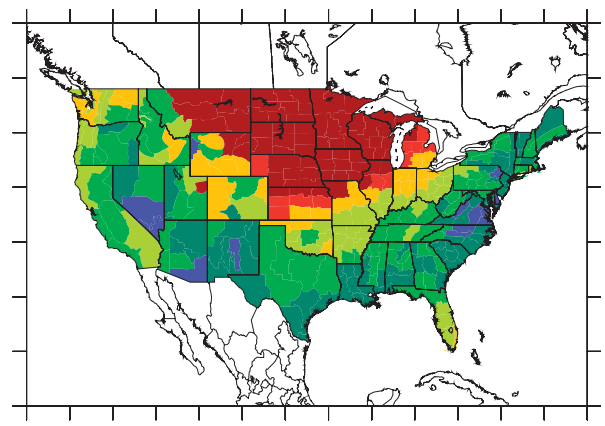

1997-98
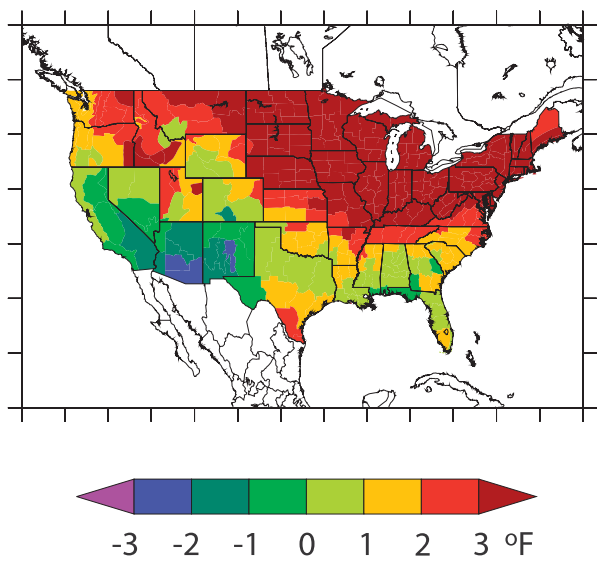

FIG. B3. Wintertime temperature anomalies during the four OLR-El Niño years. 


\section{DJF Temperature Anomalies}

1987-88

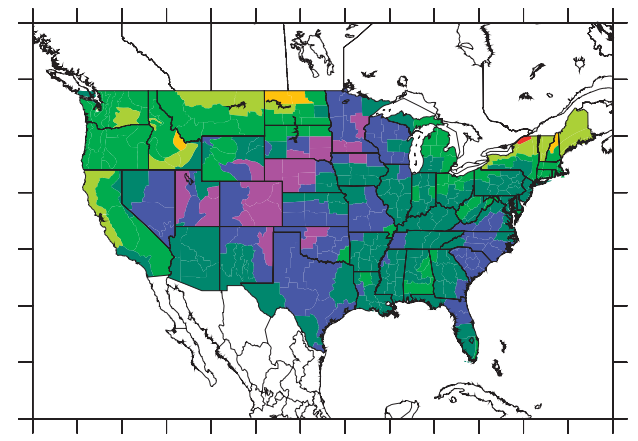

2002-03

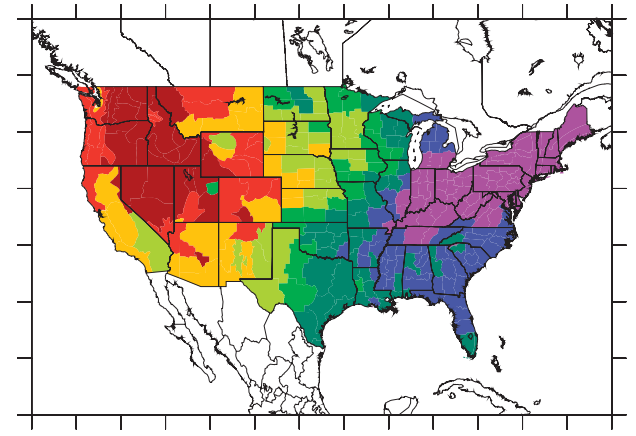

1994-95

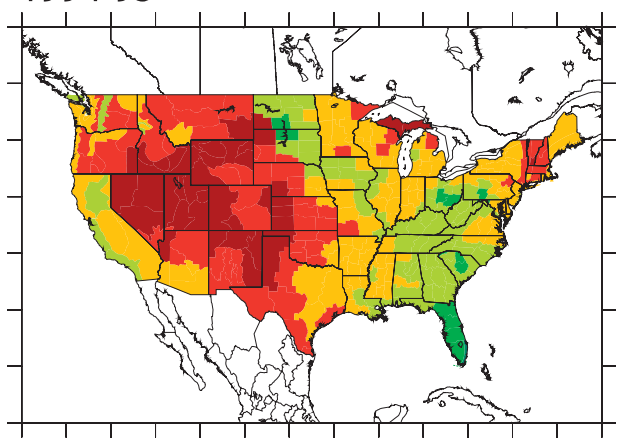

2004-05

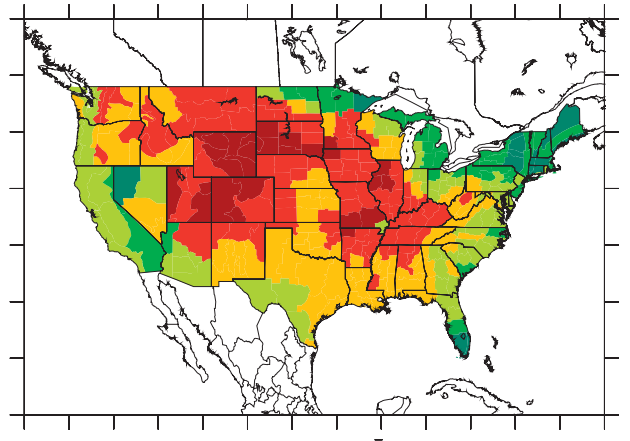

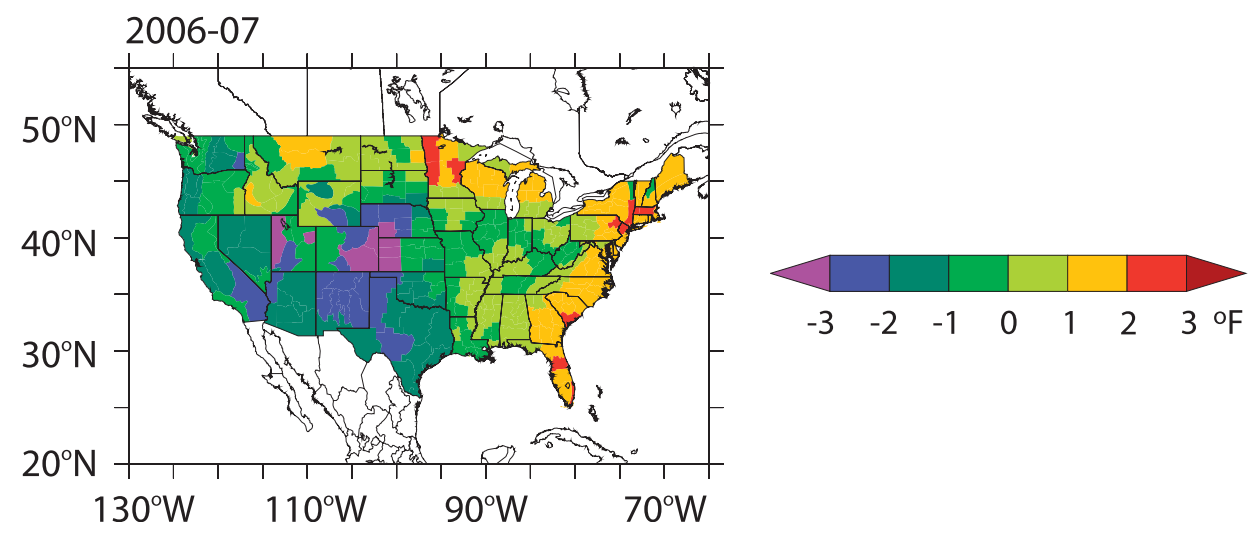

FIG. B4. Wintertime temperature anomalies during the five non-OLR-El Niño years. 


\section{DJF Precipitation Anomalies}

\section{2-83}

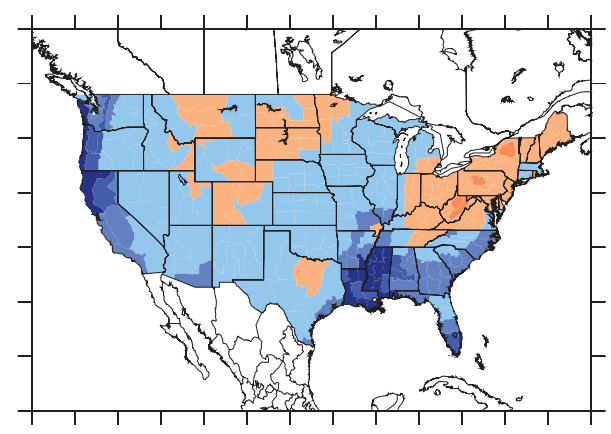

1991-92

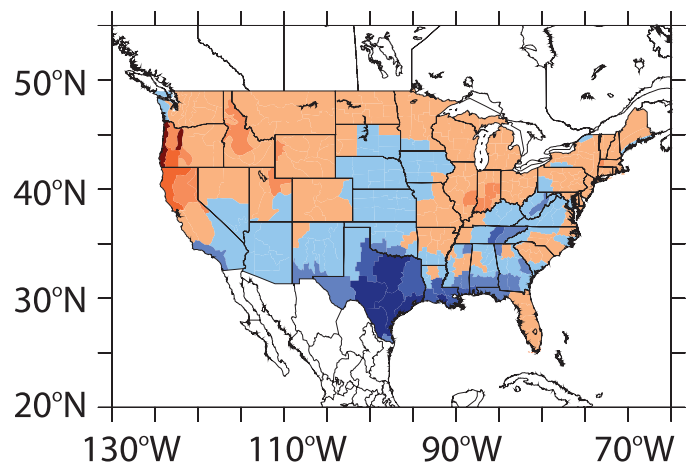

1986-87

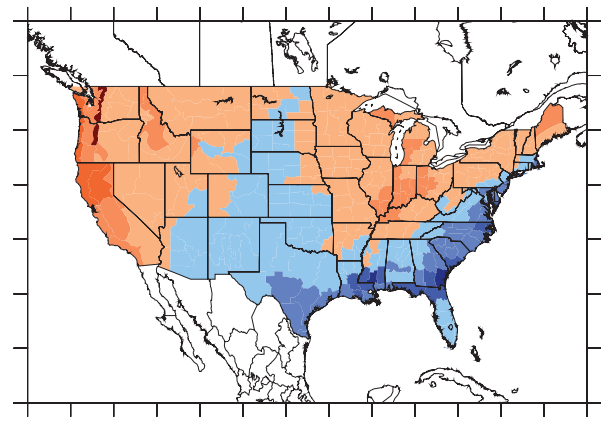

1997-98

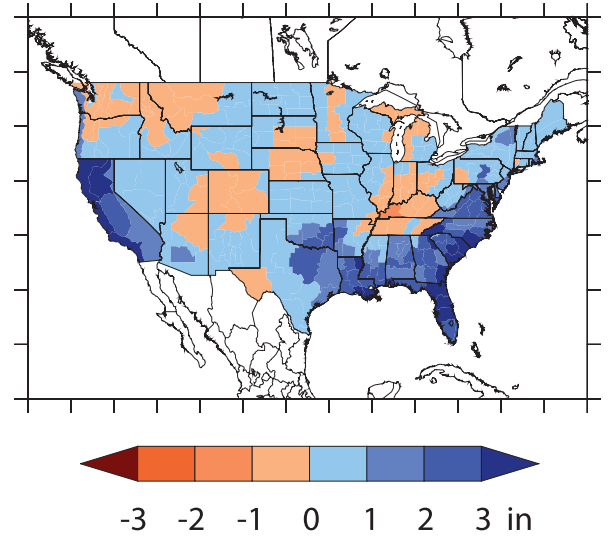

FIG. B5. Wintertime precipitation anomalies during the four OLR-El Niño years. 


\section{DJF Precipitation Anomalies}
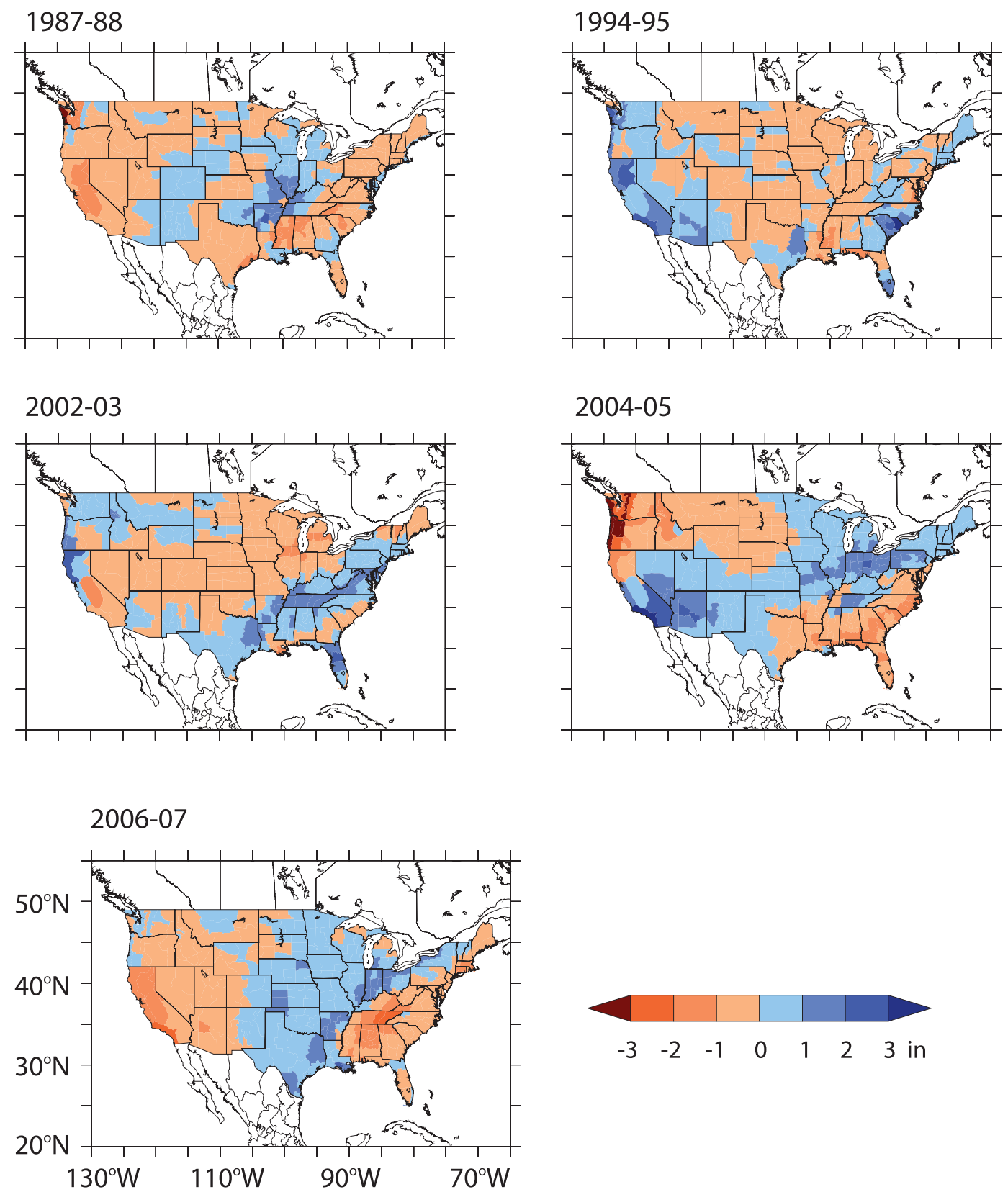

FIG. B6. Wintertime precipitation anomalies during the five non-OLR-El Niño years. 
SON

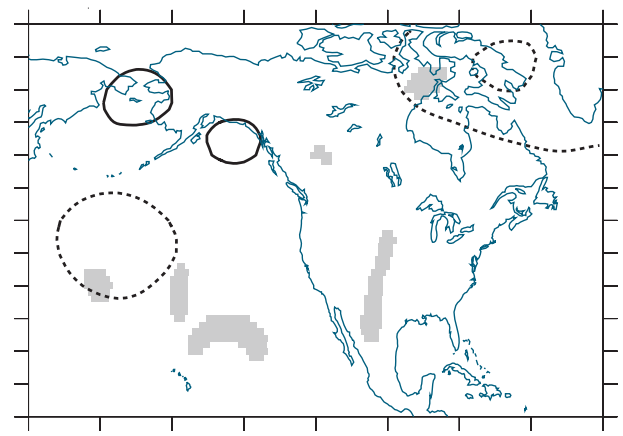

NDJ

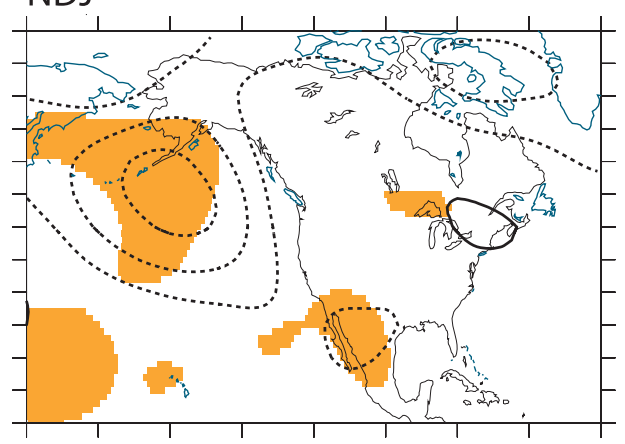

JFM

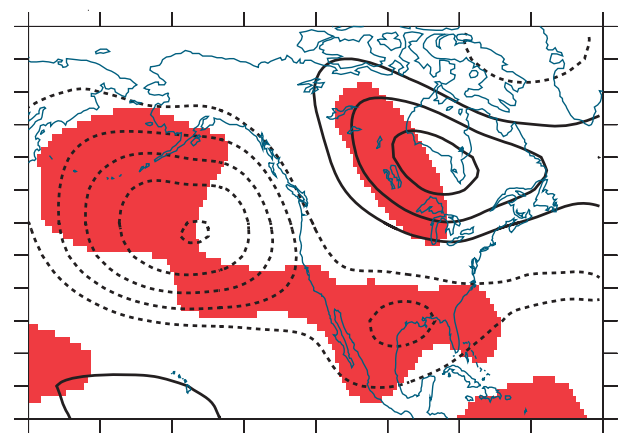

OND

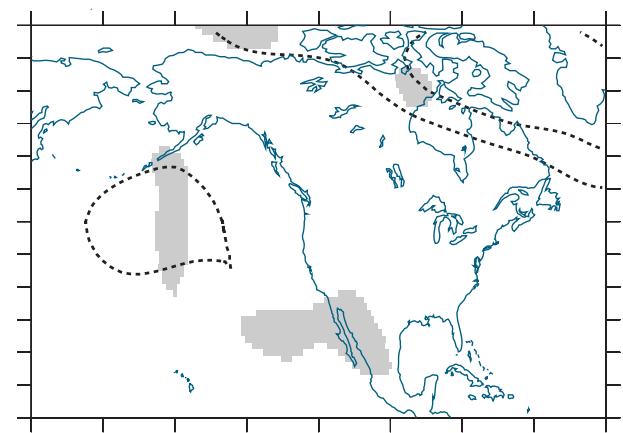

DJF

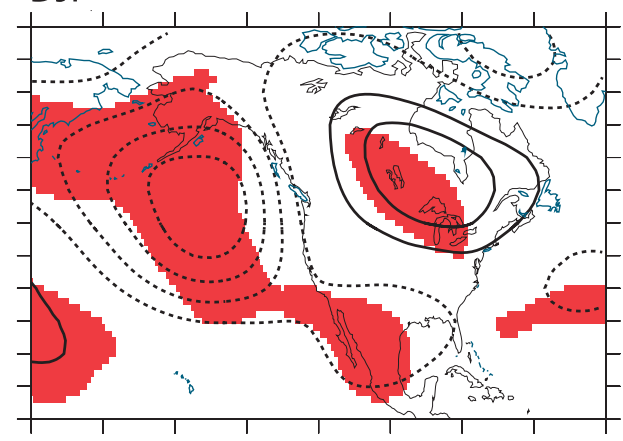

FMA

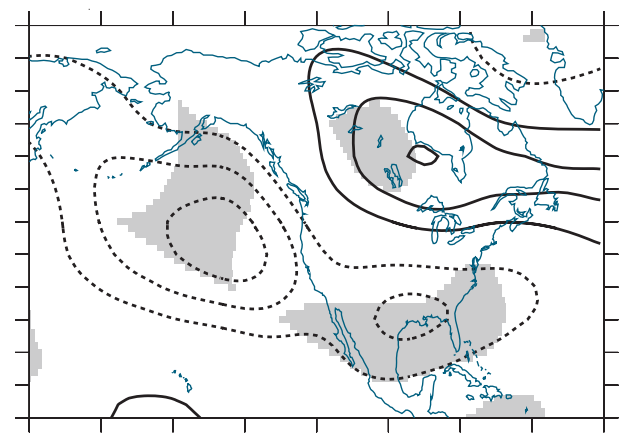

MAM

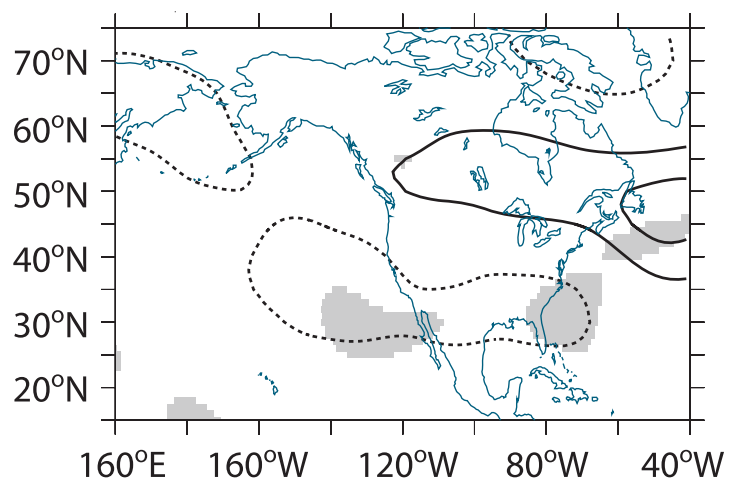

Contours every $20 \mathrm{~m}$

Shading at $95 \%$ local significance:

not field significant

$90 \%$ field significance

95\% field significance

FIG. C1. OLR-El Niño event composite geopotential height anomalies. 


\section{REFERENCES}

Chiodi, A. M., and D. E. Harrison, 2010: Characterizing warmENSO variability in the equatorial Pacific: An OLR perspective. J. Climate, 23, 2428-2439.

Efron, B., and R. Tibshirani, 1991: Statistical data analysis in computer age. Science, 253, 390-395.

Harrison, D. E., and N. K. Larkin, 1998: Seasonal U.S. temperature and precipitation anomalies associated with El Niño: Historical results and comparison with 1997-1998. Geophys. Res. Lett., 25, 3959-3962.

Hoerling, M. P., and A. Kumar, 2002: Atmospheric response patterns associated with tropical forcing. J. Climate, $\mathbf{1 5}$, 2184-2203.

Kalnay, and Coauthors, 1996: The NCEP/NCAR 40-Year Reanalysis Project. Bull. Amer. Meteor. Soc., 77, 437-470.

Kiladis, G. N., and H. Diaz, 2009: Global climatic anomalies associated with extremes in the Southern Oscillation. J. Climate, 2, 1069-1090.

Kug, J.-S., F.-F. Jin, and S.-I. An, 2009: Two types of El Niño events: Cold-tongue El Niño and warm-pool El Niño. J. Climate, 22, 1499-1515.

Larkin, N. K., and D. E. Harrison, 2005a: Global seasonal temperature and precipitation anomalies during El Niño autumn and winter. Geophys. Res. Lett., 32, L16705, doi:10.1029/ 2005 GL022860.
— , and —_, 2005b: On the definition of El Niño and associated seasonal average U.S. weather anomalies. Geophys. Res. Lett., 32, L13705, doi:10.1024/2005GL022738.

Liebmann, B., and C. A. Smith, 1996: Description of a complete (interpolated) outgoing longwave radiation dataset. Bull. Amer. Meteor. Soc., 77, 1275-1277.

Livezey, R. E., and W. Y. Chen, 1983: Statistical field significance and its determination by Monte Carlo techniques. Mon. Wea. Rev., 111, 46-59.

Ropelewski, C. F., and M. S. Halpert, 1996: Quantifying Southern Oscillation-precipitation relationships. J. Climate, 9, 10431059.

Smith, S. R., D. M. Legler, M. J. Remigio, and J. J. O' Brien, 1999: Comparison of $1997 / 98$ U.S. temperature and precipitation anomalies to historical ENSO warm phases. J. Climate, 12, $3507-3515$

Wallace, J. M., and D. S. Gutzler, 1981: Teleconnections in the geopotential height field during the Northern Hemisphere winter. Mon. Wea. Rev., 109, 784-812.

Weng, H., S. K. Behera, and T. Yamagata, 2009: Anomalous winter climate conditions in the Pacific Rim during recent El Niño Modoki and El Niño events. Climate Dyn., 32, 663674.

Wolter, K., R. M. Dole, and C. A. Smith, 1999: Short-term climate extremes over the continental United States and ENSO. Part I: Seasonal temperatures. J. Climate, 12, 3255-3272. 